\title{
Zur Kritik der Arbeit: „,Der Klammerreflex nach Sympathicus- exstirpation" von Spiegel und Sternschein, aus dem neurolog. Institut der Wiener Univ. [Vorstand: Prof. Dr. 0. Marburg].
}

\author{
Von
}

\author{
Prof. Dr. R. H. Kahn.
}

(Aus dem physiologischen Institute der deutschen Universität in Prag.)

(Eingegangen am 20. März 1922.)

Auf S. 115 des 192. Bandes von Pflügers Archiv anschließend an eine Arbeit von mir ${ }^{1}$ ) über den gleichen Gegenstand haben $E$. A. Spiegel und $E$. Sternschein eine Untersuchung veröffentlicht, als deren Resultat sie angeben, daß ,der efferente Schenkel des Klammerreflexes des brünstigen Frosches nicht über den Grenzstrang verläuft". Diesen Schlußsatz, dessen Richtigkeit aus meinen erwähnten Ausführungen hervorgeht, an das Ende ihrer Arbeit zu stellen, sind Spiegel und Sternschein durchaus nicht berechtigt. Nämlich in dem Sinne, in dem sie ihn verstanden wissen wollen, als einen Beitrag zur Frage der tonischen Innervation. Denn die Untersuchungen der beiden Autoren sind methodisch so unvollkommen, daß aus ihnen für oder wider eine sympathische Innervation der Umklammerungsmuskeln garnichts hervorgeht.

Spiegel und Sternschein haben 12 ,Frösche" derart operiert, daß sie an dem Tiere, ,dessen Klammerreflex durch Äthernarkose gelöst" war, von der rechten Seite her nach Eröffnung der Peritonealhöhle und des Sinus subvertebralis das III. und IV. sympathische Ganglion nebst einem Stïcke des Grenzstranges der rechten Seite exstirpierten. Vom Gelingen dieser Operation überzeugten sie sich „durch den histologischen Nachweis der exstirpierten Ganglien, sowie duroh die Beobachtung einer vorübergehenden GefäBstase an den Schwimmbäuten der operierten Extremitäten." (Die „Frösche“ von Spiegel und Sternschein hatten also an den vorderen Extremitäten Schwimmhäute). Die Verengerung der Pupille der operierten Seite aber, das am meisten charakteristische Phänomen nach einseitiger Ausrottung der Pars brachialis des Sympathicus haben die Autoren übersehen.

An den so operierten Fröschen stellten die Autoren fest, daß die Tiere nach Erholung von der Äthernarkose, an den Beinen in die Höhe gehalten, die ,um ein Vielfaches" schwereren Weibchen umklammert trugen, ohne daß sich die Extremität der operierten Seite gegenüber der der gesunden schwächer erwiesen hätte. Ebensowenig ließ sich, wenn man durch symmetrisches Vorschieben eines Keiles zwischen den Rücken des Weibchens und den Bauch des Männchens das letztere abzuheben suchte, die Umklammerung auf der Seite des operierten Armes früher

1) R. H. Kahn, Beiträge zur Lehre vom Muskeltonus. II. Zustand und Innervation der Muskeln der vorderen Extremitäten des Frosches während der Umklammerung. Pflügers Arch. f. d. des. Physiol. 192, 93. 1921. 
lösen, als auf der Gegenseite. War der Reflex nach der Operation nicht gleich wieder auslösbar, dann haben die Autoren von der Injektion einer Aufschwemmung von Testikelsubstanz nach Steinach prompte Erfolge gesehen. Die Reflexerregbarkeit ließ sich dadurch wieder herstellen, wobei keine Differenz an den beiden vorderen Extremitäten festzustellen war.

Aus der Anstellung dieser Untersuchungen geht hervor, daß Spiegel und Sternschein der Unterschied zwischen der Umklammerung aus tetanischer, alterativer Innervation der Armmuskeln und dem ruhigen, tonischen, dauernden Verkürzungs- bzw. Spannungszustande, der „,Sperre“ der umklammernden Muskeln gar nicht klar geworden ist. Das, was die Autoren bei ihren Untersuchungen geprüft haben, war der Umklammerungsreflex, welcher bei allen von den Autoren verwendeten Maßnahmen in tetanischem Festhalten des Weibchens besteht. Und je mehr man versucht, die Umklammerung zu lösen, desto mehr wird diese tetanische Muskelaktion verstärkt. Haben die Autoren etwa erwartet, daß dieses Phänomen nach einseitiger Ausrottung eventueller sympatischer Innervationswege der Muskeln leiden könnte?

Von den für die Untersuchung wichtigen Punkten erwähnen sie kein Wort. Ob die Tiere spontan umklammerten, ob sie in ruhiger, ungestörter Umklammerung tagelang fest verharrten, ob sich hier etwa ein Unterschied zwischen links und rechts zeigte, das sind die Punkte, welche zu untersuchen gewesen wären. Denn hierin und nicht im Festhalten des Weibchens bei gewaltsamen Lösungsversuchen liegt das Charakteristische der tonischen Dauerverkürzung bzw. -spannung der Umklammerungsmuskeln. Man möchte meinen, daß diese Verhältnisse Spiegel und Sternschein wenigstens nach der Lektüre meiner, der ihren vorangehenden Untersuchung klar geworden sei. Denn aus ihr hätten sie ersehen können, daß sie daß, was sie untersuchen wollten, gar nicht untersucht haben, und daß für sie kein Grund vorlag, sich ,,jenen Autoren anschließen zu müssen, welche eine Beteiligung des Sympathicus am Zustandekommen der tonischen Innervation der Skelettmuskulatur bezweifeln". Indessen scheinen die Autoren die erwähnten springenden Punkte doch nicht erkannt zu haben, denn Spiegel $^{1}$ ) schreibt am Fuße seiner nächsten Arbeit über den Muskeltonus, in welcher er seiner in Rede stehenden Untersuchungen mit Sternschein gedenkt: ,Interessanterweise kommt Kahn im gleichen Heft" (des Archivs), ,an demselben Objekt wie wir zu ganz ähnlichen Schlüssen". Aus diesem Grunde habe ich es für nötig gehalten, nochmals darauf hinzuweisen, daß in dem Phänomen der Umklammerung zwei grundverschiedene Komponenten enthalten sind. Spiegel und Sternschein haben die eine untersucht und aus den Resultaten einen Schluß auf die andere gezogen.

1) E. A. Spiegel, Untersuchungen über den Muskeltonus I. Pflügers Arch. f. d. ges. Physiol. 193, 7. 1921. 